\title{
Liver Resection for Metastatic Disease; A Population-Based Analysis of Trends
}

\author{
J.A.M. de Ridder ${ }^{a}$ V.E.P.P. Lemmens ${ }^{c, d} \quad$ L.I.H. Overbeek ${ }^{\text {e }}$ I.D. Nagtegaal ${ }^{b}$ \\ J.H.W. de Wilt ${ }^{\mathrm{a}}$ on behalf of the Dutch Liver Surgery Group
}

${ }^{a}$ Department of Surgical Oncology and b Department of Pathology, Radboud University Medical Center, Nijmegen, 'Eindhoven Cancer Registry, Comprehensive Cancer Centre South (IKZ), Eindhoven, dDepartment of Public Health, Erasmus MC University Medical Centre, Rotterdam, and eFoundation PALGA, Nationwide Network and Registry of Histo- and Cytopathology in The Netherlands, Utrecht, The Netherlands

\section{Key Words \\ Liver metastases · Resection · Population-based study . \\ Origin of the primary tumor $\cdot$ Trends}

\begin{abstract}
Objective: The study aims to evaluate all patients who underwent liver resection for metastatic disease for demographics, characteristics of the primary tumor and metastasis, volume of liver resection specimens per pathology laboratory and to describe trends in surgical treatment. Methods: Data were prospectively collected using the Dutch nationwide pathology network. All pathology reports containing details on liver resections for metastatic disease between January 2001 and December 2010 were evaluated. Results: A total of 3,916 liver resections were performed in 3,699 patients with a median age of 63 years (range $1-91$ ). The primary tumor was mainly colorectal ( $n=3,256 ; 88.0 \%)$. The number of 'high volume liver centers' increased from 2 to 12 in the study period, whereas the number of 'low volume centers' decreased. The number of liver resections increased from 224 to 596 per year $(p \leq 0.0001)$. A significant increase was demonstrated in elderly patients, patients with multiple metastases, liver resections for smaller metastases and mi-
\end{abstract}

nor liver resections. Conclusion: Although the majority of patients were young and had solitary metastasis, indications for liver resection are expanding as indicated by increasing numbers of elderly and patients with multiple liver metastases. Patients with non-colorectal liver metastases were seldom candidates for resection.

(c) 2016 The Author(s)

Published by S. Karger AG, Basel

\section{Introduction}

Liver resection is considered standard treatment for patients with colorectal liver metastases (CRLM), with 5 -year overall survival rates of $50 \%$ or more, depending on several clinical risk factors [1-3]. In addition, liver surgery is accepted as a treatment option in patients with neuroendocrine liver metastases (NELM), with 5-year survival ranging from 60 to $80 \%$ [4-6]. Selected patients with non-CRLM, non-NELM may also be potential candidates for surgical treatment, since several studies demonstrated an association with improved survival after liver resection [7-12].

Improvements in anesthetic techniques and post-operative care led to decreased mortality rates after liver sur- 
gery of less than $3 \%$ in experienced liver surgery centers [13-15]. With these improvements, indications for liver resection are expanding and more patients with liver metastases undergo surgical treatment $[3,16]$. Besides perioperative management improvements, innovations in surgical and non-surgical techniques such as radio frequent ablation (RFA) therapy, portal vein embolization and availability of effective neo-adjuvant systemic therapies contribute to an increase in number of liver resections $[17,18]$. In patients with initially irresectable CRLM, pre-operative chemotherapy (often in combination with targeted agents such as bevacizumab and cetuximab) led to increased response rates and therefore to an increase of resectable CRLM $[19,20]$. All these factors are important and might contribute to the growing number of liver resections.

Population-based studies have described an increase in the amount of liver resections for metastatic disease, mainly in patients with colorectal cancer. In the UK, the number of patients who will undergo liver resection when diagnosed with CRLM increased from $1.7 \%$ in 1998 to $3.8 \%$ in 2004 [21]. A similar French study reported an increase in liver resection from 2 to $20 \%$ in the period between 1976 and 2000 [22]. In both studies, only patients with liver metastases from colorectal origin were evaluated, and only few nationwide studies are available on liver resections performed for non-CRLM $[8,10,12]$.

The aim of this study is to assess changes in the number of liver resections carried out in both patients with CRLM and non-CRLM. Different factors (e.g., number or size of metastases, patient age and tumor type) were evaluated during the study period to study potential differences in indication for liver surgery. Furthermore, the number of resection specimens per pathology laboratory was evaluated, in order to demonstrate the centralization of liver surgery.

\section{Methods}

\section{Patients and Data Collection}

Data were collected using a query in the PALGA database. This nationwide network and registry of histopathology and cytopathology in the Netherlands has been collecting pathology reports since 1971, with a nationwide coverage since 1991 [23]. The search terms 'liver metastases' and 'histology' were used in the PALGA database to identify all pathology reports containing details of liver metastases between January 2001 and December 2010. Patients who underwent liver resection for a primary liver malignancy or a benign liver lesion were excluded from this study. When the origin of the primary tumor was not described in the pathology report, all pathology reports of that specific patient were critically re- viewed in order to obtain the origin of the primary tumor. Both the privacy committee and scientific committee of PALGA approved the study design.

The following characteristics were collected from the pathology reports per patient: year of liver resection, age at time of resection, gender, location of the primary tumor, tumor type, number and size of the liver metastases and the completeness of the resection.

Tumor typing was performed according to the International Classification of Diseases-10. Neuroendocrine carcinoma included all types of neuroendocrine tumors (low and high grade). Primary tumors were classified according to the organ system of the primary tumor. Primary tumor location was classified as 'not otherwise specified' (NOS), if no definite origin was reported.

The type of liver resection was derived from the pathology report. A minor resection was defined as a resection of 3 or less liver segments. A major resection was defined as a resection of more than 3 liver segments. A re-resection was considered to be a scheduled '2-stage procedure' when patients underwent a re-resection within 3 months after the initial liver resection. These procedures were classified by definition as major resections.

Liver resection was considered a complete resection (R0) when the pathologist described free resection margins. Details regarding distance of resection margins were not described in all pathology reports and therefore not recorded in the current study. The difference between microscopic incomplete (R1) and macroscopic incomplete resections (R2) was not always clearly reported, and therefore, both were analyzed as one group of incomplete resections. The size of the largest liver metastasis was reported in patients with multiple liver metastases.

Pathology reports in the PALGA database are registered anonymously, without details and names of the hospitals and surgeons, which delivered the resection specimen. The pathology laboratories where the specimens were assessed were registered. Since all hospitals in the Netherlands where liver surgery is performed have their own pathology laboratory, the number laboratories is a reliable reflection of the number of hospitals. Laboratories that examine one or less liver resection specimen per year were defined as 'incidental' centers. These centers were not included in the analysis of hospital volume. 'Low volume centers' were defined as laboratories that examine 2-9 liver resection specimens per year; laboratories that examine 10-19 liver resection specimens per year were defined as 'middle volume', and 'high volume centers' were defined as laboratories that examine more than 20 liver resection specimens yearly.

\section{Statistics}

The Mann-Whitney U test was used to compare medians between the group of patients with CRLM and the non-CRLM group. To compare nominal variables, the Pearson chi-square test was used. Multivariate logistic regression analyses were used to determine the independent effect of the time period of diagnosis on the chance to undergo liver resection. Stratification was carried out for size and number of metastases, type of resection and resection margins. Multivariate regression analyses were used to assess differences in tumor and patient characteristics between 'high', 'middle' and 'low volume centers'. A p value of $<0.05$ was considered statistically significant. All descriptive and statistical analyses were performed using Statistical Package for Social Sciences version 18.0 (SPSS Inc., Chicago, Ill., USA). 
Table 1. Primary tumor locations in patients with liver metastases from carcinoma who underwent liver resection

\begin{tabular}{|c|c|c|c|c|}
\hline & \multirow[t]{2}{*}{$\mathrm{n}$} & \multicolumn{2}{|l|}{ Sex, n (\%) } & \multirow{2}{*}{$\begin{array}{l}\text { Age, years, } \\
\text { median (range) }\end{array}$} \\
\hline & & male & female & \\
\hline \multicolumn{5}{|l|}{ Head/neck } \\
\hline Total & 12 & $9(75.0)$ & $3(25.0)$ & $49(17-65)$ \\
\hline Pharynx/larynx & 3 & $3(100)$ & - & $56(32-58)$ \\
\hline Thymus & 2 & $2(100)$ & - & $44(35-52)$ \\
\hline Thyroid gland & 7 & $4(57.1)$ & $3(42.9)$ & $48(17-65)$ \\
\hline \multicolumn{5}{|l|}{ Digestive system } \\
\hline Total & 3,391 & $2,065(60.9)$ & $1,326(39.1)$ & $64(24-94)$ \\
\hline Colon/rectum/appendix & 3,238 & $1,983(61.2)$ & $1,255(38.8)$ & $64(24-94)$ \\
\hline Anus & 3 & $1(33.3)$ & $2(66.7)$ & $53(45-59)$ \\
\hline Stomach & 20 & $17(85.0)$ & $3(15.0)$ & $68(36-79)$ \\
\hline Esophagus & 15 & $11(73.3)$ & $4(26.7)$ & $60(35-73)$ \\
\hline Gall bladder/biliary tract & 22 & $7(27.3)$ & $16(72.7)$ & $66(52-86)$ \\
\hline Pancreas & 51 & $28(54.9)$ & $23(45.1)$ & $62(34-82)$ \\
\hline Duodenum/small intestine & 25 & $9(36.0)$ & $16(64)$ & $59(45-75)$ \\
\hline NOS & 17 & $9(52.9)$ & $8(47.1)$ & $62(38-86)$ \\
\hline Lung & 7 & $4(57.1)$ & $3(42.9)$ & $64(52-76)$ \\
\hline Skin & 1 & - & $1(100)$ & 47 \\
\hline Breast & 32 & - & $32(100)$ & $51(31-82)$ \\
\hline \multicolumn{5}{|l|}{ Genital tract } \\
\hline Total & 39 & - & $39(100)$ & $58(28-85)$ \\
\hline Ovary & 35 & - & $35(100)$ & $56(28-85)$ \\
\hline Uterus & 2 & - & $2(100)$ & $66(61-71)$ \\
\hline Cervix & 2 & - & $2(100)$ & $55(51-58)$ \\
\hline \multicolumn{5}{|l|}{ Urological tract } \\
\hline Total & 33 & $21(63.6)$ & $12(36.4)$ & $58(20-79)$ \\
\hline Kidney & 26 & $15(57.7)$ & $11(42.3)$ & $65(20-79)$ \\
\hline Urinary bladder & 4 & $3(75.0)$ & $1(25.0)$ & $68(62-77)$ \\
\hline Prostate & 1 & $1(100)$ & - & 61 \\
\hline Testis & 2 & $2(100)$ & - & $48(27-68)$ \\
\hline Adrenal & 4 & $2(50)$ & $2(50)$ & $64(59-68)$ \\
\hline Other & 2 & $1(50)$ & $1(50)$ & $64(59-68)$ \\
\hline NOS & 36 & $12(33.3)$ & $24(66.7)$ & $62(17-79)$ \\
\hline Total & 3,557 & 2,114 & 1,443 & \\
\hline
\end{tabular}

\section{Results}

\section{General Patient Characteristics}

A total number of 24,138 pathology reports describing histologically confirmed liver metastases between 2001 and 2010 were identified and reviewed from the PALGA database. The majority of these reports $(n=20,222)$ described results of liver biopsies for metastatic disease and were excluded from the present study. The remaining 3,916 pathology reports described liver resections for metastatic disease and were included in the present study. Resections were performed in 3,699 patients (59\% men and $41 \%$ women). During the study period, 203 patients $(5.5 \%)$ underwent a re-resection and 14 patients underwent a third resection. Median age at the time of the pri- mary liver resection was 63 years (range 1-91 years). The 1 -year-old patient underwent a liver resection for metastatic Wilms tumor.

\section{Primary Tumor Characteristics}

Most of the liver resections were performed in patients with metastatic carcinoma ( $\mathrm{n}=3,557 ; 96.2 \%)$, mostly located in the colon or rectum $(\mathrm{n}=3,238 ; 82.7 \%)$. Metastatic melanoma $(\mathrm{n}=36 ; 1.0 \%)$ and metastatic sarcoma $(\mathrm{n}=46 ; 1.2 \%)$ were rare indications for liver resection (online suppl. table, see www.karger.com/ doi/10.1159/000441802). Other locations of carcinomas are presented in table 1. Tumor subtypes in CRLM from carcinoma were adenocarcinoma NOS $(n=3,224)$, neuroendocrine carcinoma $(\mathrm{n}=11)$ and squamous cell car- 
cinoma $(\mathrm{n}=3)$. The tumor type was not reported in 15 patients with metastases from colorectal origin. In 3 patients, a GIST was diagnosed as the tumor subtype in liver metastases originating from a colorectal primary tumor. Besides colon or rectum, other primary GIST locations were stomach $(n=7)$, duodenum or small intestine $(\mathrm{n}=10)$ and digestive tract NOS $(\mathrm{n}=1)$.

Patients who underwent liver resection for nonCRLM were younger at the time of operation (median 59 years, range 1-86 years) compared to patients with CRLM (median 64 years, range 24-91 years; $\mathrm{p} \leq 0.0001$ ). Patients with CRLM were predominantly men (61.4\%), whereas patients who underwent resection for nonCRLM were mostly women (58.1\%; $\mathrm{p} \leq 0.0001)$. Female predominance in patients with non-CRLM can be explained by 52 patients $(11.9 \%)$ with metastatic gynecological tumors (cervix $n=3$; uterus $n=9, n=3$; and ovary $n=40)$ and 32 patients $(7.2 \%)$ with metastatic breast carcinoma.

\section{Liver Resections}

Minor resections were performed in 2,336 patients (59.7\%), mostly a segmentectomy $(\mathrm{n}=1,483 ; 63.5 \%)$. A non-anatomical resection was performed in 834 patients (35.7\%). In 19 patients $(0.8 \%)$, the resection type was not specified. Hemihepatectomy was performed in 974 patients (24.9\%), right-sided hemihepatectomy in 572 patients (14.6\%), left sided hemihepatectomy in $171 \mathrm{pa}$ tients (4.4\%) and 117 patients (3.0\%) underwent an extended hemihepatectomy. The side of the hepatectomy was not specified in 114 patients (2.9\%).

A complete resection (R0) was performed in 3,058 patients $(78.1 \%), 482$ patients (12.3\%) underwent an incomplete resection (R1 or R2), and in 376 patients $(9.6 \%)$, the resection margins were not described. The median number of resected metastases was 1 (range 1-19) and the median size was $34.0 \mathrm{~mm}$ (range 1-280 mm).

\section{Re-Resections and '2-Stage Procedures'}

During the study period, 203 patients (5.5\%) underwent a re-resection, mostly for CRLM ( $\mathrm{n}=183$; 95.3\%). Eleven patients underwent a re-resection as part of an intended '2-stage procedure', after a median of 42 days (range 21-84 days) from the initial liver resection. The remaining 192 patients underwent a re-resection as a result of disease recurrence; 14 patients underwent a third liver resection. Patients who underwent a re-resection were significantly younger (median 61 years, range $24-78$ years) compared to patients who underwent a single liver resection (median 63 years, range 1-91 years; $p=0.042$ ).
The re-resection was performed after a median of 12 months (range 3-73 months) from the initial liver resection.

\section{Liver Resections Per Pathology Laboratory}

The number of pathology laboratories examining liver resection specimens decreased from 37 in 2001 to 31 in 2010. Especially the 'low volume' and 'sporadic centers' decreased from 15 respectively 11 in 2001, to 10 respectively 2 in 2010 (fig. 1). A median of 28 resection specimens (range 20-84) were evaluated annually in 'high volume centers'. 'Middle volume centers' examined 13 resection specimens (range 10-19) per year, and in 'low volume centers', 4 resection specimens (range 2-9) were evaluated yearly.

In 'high volume centers', resection specimens with multiple metastases (OR 1.348, 95\% CI 1.069-1.701) and non-CRLM (OR 1.397, 95\% CI 1.216-3.452) were more often examined than in 'middle' and 'low volume centers'. Furthermore, in 'high volume centers' patients were younger ( $<75$ years) at the time of liver resection compared to 'low' and 'middle volume centers' (OR 0.564, $95 \%$ CI $0.423-0.754)$. No differences were observed in the amount of complete (R0) resections and in the size of the liver metastases between the 'high', 'middle' and 'low volume centers' (table 2).

\section{Trends in Liver Resections}

The annual number of liver resections increased from 224 in 2001 to 596 in 2010 ( $p \leq 0.0001$ ). This increase was mainly due to an increase in liver resections for CRLM. The number of liver resections performed for non-CRLM remained almost stable (fig. 2). The percentage of re-resections increased not significantly, from $3.9 \%$ in the period between 2001 and 2004 to $5.0 \%$ between 2008 and 2010.

In 2001, the median age at the time of liver resection was 62 years (range $1-85$ years), which increased to a median age of 64 years (range 28-89 years) in 2010 ( $\mathrm{p} \leq$ 0.0001 ). The higher age was also demonstrated by the percentage of elderly patients ( $>75$ years) who underwent liver resection. Between 2001 and 2004, 9.1\% of the patients undergoing a liver resection were older than 75 years, which increased to $13.9 \%$ between 2008 and 2010 (OR 1.61, 95\% CI 1.25-2.07).

Between 2001 and 2004, liver resections were mainly performed for solitary metastasis (67.2\%), which decreased to $60.5 \%$ between 2008 and 2010. In this time period, more liver resections were performed for multiple liver metastases (OR 1.34, 95\% CI 1.13-1.58; table 3). 
Fig. 1. Amount of liver resections performed in high $(\geq 20$ liver resections per year), middle (10-19 liver resections per year) and low volume centers ( $\leq 1$ liver resections per year). Below the figure is the number of pathology (PA) laboratories involved in examining liver resection specimens per year.

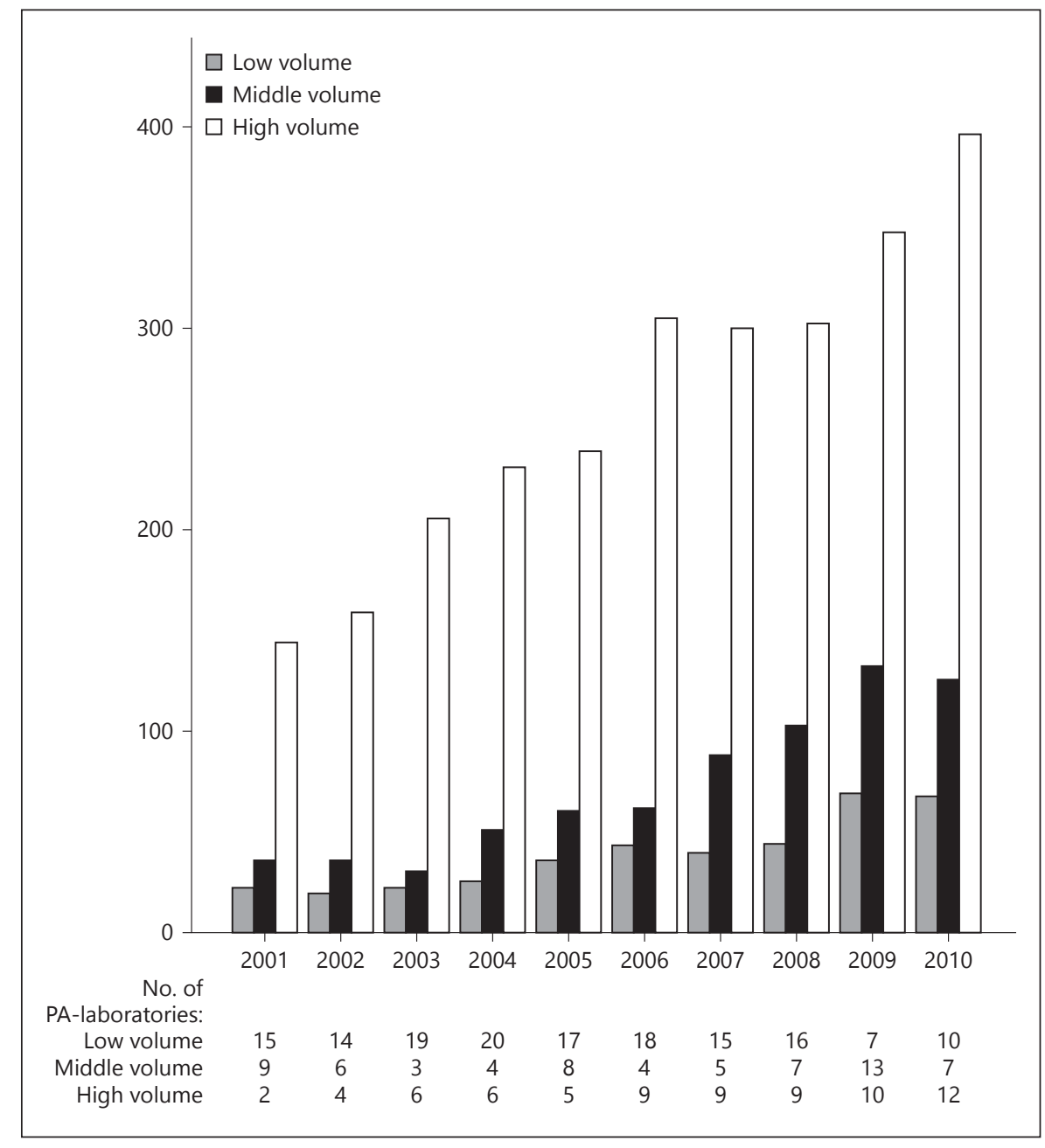

During the study period, an increase in percentage of small metastases $(\leq 50 \mathrm{~mm})$ was demonstrated. In the period between 2001 and $2004,70.8 \%$ of the metastases were $50 \mathrm{~mm}$ or smaller, which increased to $79.7 \%$ between 2008 and 2010 (OR 1.62, 95\% CI 1.27-2.07). This coincided with an increase in minor resections from $63.5 \%$ between 2001 and 2004 to $74.7 \%$ between 2008 and 2010 (OR 1.69, 95\% CI 1.41-2.03; table 3).

\section{Discussion}

The current study describes all liver resections performed in the last decade for metastatic disease in the Netherlands. A significant increase in number of liver resections was demonstrated, predominantly in patients with CRLM. Part of this increase may be explained by the increasing incidence of primary colorectal carcinoma and, as a result, CRLM. Additional explanations for the increase in resections can be found in the expansion of indications for liver resection.

A significant increase of patients' age at the time of resection was demonstrated, as well as an increase in the percentage of elderly patients ( $>75$ years). There is controversy in the literature whether these elderly patients have an increased risk of postoperative complications and mortality. Some reports suggest that complication rates may be increased [24], whereas others report similar complication rates irrespective of age [24-26]. The trend toward operating more elderly patients, as observed in the current study, suggests that age is no longer considered a contraindication for liver resection. Data on comorbidity and clinical condition of the patient were not available in the current study, but these factors may very well be more important in judging patients fit for surgery. 
Fig. 2. Number of liver resections per-

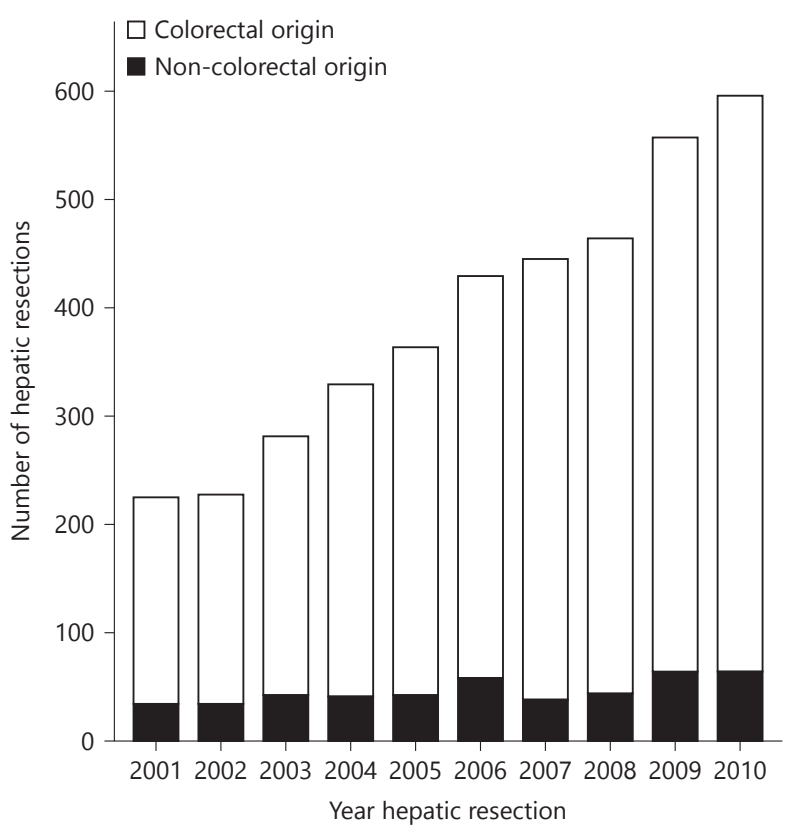

formed for metastatic disease.

Table 2. Patterns in resection characteristics in low (1-9 liver resections per year), middle (10-19 liver resections per year) and high volume centers ( $\geq 20$ liver resections per year) (logistic regression)

\begin{tabular}{|c|c|c|c|}
\hline & $\begin{array}{l}\text { Low volume* } \\
(\mathrm{n}=390)\end{array}$ & $\begin{array}{l}\text { Middle volume } \\
(\mathrm{n}=723)\end{array}$ & $\begin{array}{l}\text { High volume } \\
(\mathrm{n}=2,629)\end{array}$ \\
\hline \multicolumn{4}{|l|}{ Size, $\mathrm{mm}$} \\
\hline$\leq 50$ & $111(75.5)$ & $346(82.0)$ & $1,201(76.4)$ \\
\hline$>50$ & $36(24.5)$ & $76(18.0)$ & $371(23.6)$ \\
\hline NR & 243 & 301 & 1,057 \\
\hline OR ( $\leq 50$ vs. $>50)(95 \% \mathrm{CI})$ & - & $1.477(0.941-2.317)$ & $1.050(0.708-1.556)$ \\
\hline \multicolumn{4}{|l|}{ Number of metastases } \\
\hline Solitary & $251(67.8)$ & $443(64.3)$ & $1,549(61.0)$ \\
\hline Multiple & $119(32.2)$ & $246(35.7)$ & $990(39.0)$ \\
\hline NR & 20 & 34 & 90 \\
\hline OR (multiple vs. solitary) (95\% CI) & - & $1.171(0.896-1.531)$ & $1.348(1.069-1.701)^{* *}$ \\
\hline \multicolumn{4}{|l|}{ Resection margins } \\
\hline R0 & $305(87.1)$ & $597(90.3)$ & $2,064(85.6)$ \\
\hline $\mathrm{R} 1 / 2$ & $45(12.9)$ & $64(9.7)$ & $348(14.4)$ \\
\hline NR & 40 & 62 & 217 \\
\hline OR (R1/2 vs. R0) (95\% CI) & - & $0.727(0.484-1.090)$ & $1.143(0.819-1.594)$ \\
\hline \multicolumn{4}{|l|}{ Type metastases } \\
\hline Colorectal & $354(90.8)$ & $661(91.4)$ & $2,302(87.6)$ \\
\hline Non-colorectal & $36(9.2)$ & $62(8.6)$ & $327(12.4)$ \\
\hline OR (CRLM vs. non-CRLM) (95\% CI) & - & $0.922(0.600-1.419)$ & $1.397(1.216-3.452)^{* *}$ \\
\hline \multicolumn{4}{|l|}{ Age, years } \\
\hline$<75$ & $322(82.6)$ & $629(87.0)$ & $2,349(89.3)$ \\
\hline$\geq 75$ & $68(17.4)$ & $94(13.0)$ & $280(10.7)$ \\
\hline OR (<75 vs. $\geq 75)(95 \% \mathrm{CI})$ & - & $0.708(0.504-0.994)$ & $0.564(0.423-0.754)$ \\
\hline
\end{tabular}

$\mathrm{NR}=$ Not reported. Values are $\mathrm{n}(\%)$ unless otherwise indicated. ${ }^{*}$ Low volume center was the reference for logistic regression; ${ }^{* *}$ statistically significant with a $\mathrm{p}$ value $<0.05$. 
Table 3. Annual patterns in resection characteristics (logistic regression)

\begin{tabular}{|c|c|c|c|}
\hline & $2001-2004^{*}$ & $2005-2007$ & $2008-2010$ \\
\hline \multicolumn{4}{|l|}{ Size, $\mathrm{mm}$} \\
\hline$\leq 50$ & $364(70.8)$ & $526(79.1)$ & $798(79.7)$ \\
\hline$>50$ & $150(29.2)$ & $139(20.9)$ & $203(20.3)$ \\
\hline NR & 547 & 573 & 616 \\
\hline OR ( $\leq 50$ vs. $>50)(95 \% \mathrm{CI})$ & - & $1.559(1.194-2.036)^{* *}$ & $1.620(1.268-2.069)^{* *}$ \\
\hline \multicolumn{4}{|l|}{ Number of metastases } \\
\hline Solitary & $684(67.2)$ & $761(63.9)$ & $940(60.5)$ \\
\hline Multiple & $334(32.8)$ & $429(36.1)$ & $613(39.5)$ \\
\hline NR & 43 & 48 & 64 \\
\hline OR (multiple vs. solitary) (95\% CI) & - & $1.154(0.968-1.377)$ & $1.335(1.132-1.576)^{* *}$ \\
\hline \multicolumn{4}{|l|}{ Type of liver resection } \\
\hline Minor & $540(63.5)$ & $730(68.9)$ & $1,066(74.5)$ \\
\hline Major & $314(36.5)$ & $332(31.1)$ & $367(25.5)$ \\
\hline NR & 207 & 176 & 184 \\
\hline OR (major vs. minor) (95\% CI) & - & $1.279(1.057-1.546)^{* *}$ & $1.689(1.407-2.028)^{* *}$ \\
\hline \multicolumn{4}{|l|}{ Resection margins } \\
\hline R0 & $796(85.7)$ & $966(87.1)$ & $1,296(86.3)$ \\
\hline $\mathrm{R} 1 / 2$ & $133(14.3)$ & $143(12.9)$ & $206(13.7)$ \\
\hline NR & 132 & 129 & 115 \\
\hline OR (R1/2 vs. R0) (95\% CI) & & $0.886(0.687-1.142)$ & $0.951(0.752-1.204)$ \\
\hline
\end{tabular}

NR $=$ Not reported. Values are $\mathrm{n}(\%)$ unless otherwise indicated. * 2001-2004 was the reference period for logistic regression; ${ }^{* *}$ statistically significant with $\mathrm{p}$ value $<0.05$. Note that all of the patients who underwent a 2-staged procedure had multiple metastases and underwent a major resection.

The percentage of patients with multiple liver metastases who underwent resection increased. Between 2001 and 2004 , only $32.8 \%$ of the liver resections were performed for multiple metastases, which increased to $39.5 \%$ between 2008 and 2010. Until recently, surgery was usually only recommended for patients with up to 3 metastases and no evidence of extrahepatic disease [27]. A recent meta-analysis reported no correlation between number of metastases and survival [28]. Nowadays, multiple liver metastases are less often considered a contraindication because of the emergence of effective neo-adjuvant systemic therapy [16] and improvements in surgical strategies. With combinations of portal vein embolization [29], RFA therapies [30] or 2-staged resections [19, 31] more patients become eligible for liver resection.

Resected liver metastases were smaller in size in patients who underwent liver resection between 2008 and 2010 compared to the size of metastases resected between 2001 and 2004. Although data on neo-adjuvant systemic therapy were not available, increased neo-adjuvant treatment may be a possible explanation for the smaller metastases found in the resection specimens. Other explanations could be improved imaging techniques or more rig- orous follow-up schedules for patients suffering from colorectal cancer.

In the present study, there were no differences in the percentages of complete resections (R0) between high and low volume centers. There were also no differences in the number of $\mathrm{R} 0$ resections in patients during the study period. Due to the nature of the study and many different pathology laboratories where the liver resection specimens were evaluated, it was impossible to discriminate between $\mathrm{R} 1$ and $\mathrm{R} 2$ resections. The exact free resection margin in millimeters was absent in many pathology reports; therefore, no definite conclusion could be drawn regarding exact resection margins.

Although increasing numbers of patients in the Netherlands undergo liver resection, still relatively few patients developing CRLM undergo liver surgery. Data from the national cancer registry show an incidence of colorectal carcinoma of 12,755 patients in 2010. In recent years $21-24 \%$ of patients with colorectal cancer presented with metastatic disease (M1) at the time of diagnosis, which is approximately 3,000 patients per year [32-34]. These synchronous metastatic lesions are limited to the liver in approximately $55 \%$ of these patients $(3,000 * 0.55=$ 
1,650 patients in Dutch population annually). Recent data from the national cancer registry demonstrated that approximately $20 \%$ of colorectal cancer patients will develop metastases during follow-up [35]. This would be approximately 1,900 colorectal patients in the total Dutch colorectal cancer population, and half of these patients would have metastases limited to the liver, which should be approximately 950 patients. Of these annual 2,600 patients with liver only disease (950 metachronous and 1,650 synchronous), approximately 20\% (498 patients with CRLM) underwent liver resection in 2010, according to the results of the present study. Although not all patients who develop liver only metastases will have resectable liver metastases, the number of patients with CRLM who underwent liver resection in the Netherlands seems low. This is comparable to data from Morris et al. [21] and Manfredi et al. [22], who reported similar data. A recent study from the Eindhoven Cancer Registry in the Netherlands reported all patients with stage IV primary colorectal cancer and demonstrated that from 2004 to 2012 the number of patients who underwent liver surgery increased from 4 to $24 \%$ [36]. This percentage may be a result of the decision-making process in management of patients with liver metastases. In the Netherlands, approximately 25 hospitals are performing liver surgery, but colorectal surgery is performed in almost all hospitals ( $>85$ hospitals). When patients are diagnosed in these hospitals they are discussed in multidisciplinary teams, where a specialist liver surgeons is not always involved in these meetings. Also the presence of a dedicated medical oncologist is demonstrated to be important in considering patients suitable for neo-adjuvant chemotherapy in patients with CRLM [37]. Jones et al. [38] demonstrated that even in high-volume centers (UK cancer network), almost twothirds of patients with tumors who were deemed unresectable by non-liver surgeons were considered potentially resectable by a panel of specialist liver surgeons. On the other hand, there is also considerable inter-individual variation in the decision-making process between liver surgeons [39]. This highlights the heterogeneity of oncological liver surgery and emphasizes the importance of multidisciplinary liver tumor boards, to optimize the timing of surgical intervention and systemic treatment.

Although approximately $20 \%$ of the patients with CRLM undergo resection, non-CRLM patients are only considered to be candidates for liver resection in highly selected cases $[10,12]$. The prevailing opinion that liver resection should not be considered as a curative option in non-CRLM patients may be insufficient, because 5-year disease-free survival after liver resection has been report- ed $[10,12,40]$. One of the reasons that non-CRLM patients might not be considered eligible for surgery is the fact that metastases are often diagnosed in an advanced disease stage, because imaging of the liver is not part of routine follow-up for many malignancies. Another reason may be that patients with non-CRLM are often not exposed to liver surgeons. With the emergence of multidisciplinary tumor boards it may be assumed that surgeons take part in the decision making process concerning the treatment of non-CRLM patients more often than in the past when this group of patients was mainly treated by medical oncologists.

Centralization of complex upper gastrointestinal surgery, especially liver surgery and the beneficial effect on outcome have been reported [41]. Centralization of liver surgery in the Netherlands led to more 'high volume' and less 'low volume' and 'sporadic centers', as observed in the current study. Although it may be assumed that centralization of liver resections may have led to improved shortand long-term outcome, this could not be drawn from the present study, because follow-up data are lacking.

In conclusion, the number of liver resections performed for metastatic disease increased over the past decade. Indications for liver resection seem to be expanding, reflected by the increasing percentage of elderly patients and the increasing amount of liver resections for multiple metastases. However, still only a minority of patients with liver metastases undergo liver resection. Therefore, we recommend that all patients with liver metastases (colorectal and non-CRLM) should be discussed in a multidisciplinary tumor board, including an expert liver surgeon, in order to offer the best possible treatment.

\section{Disclosure Statement}

None.

References

\footnotetext{
1 House MG, Ito H, Gonen M, Fong Y, Allen PJ, DeMatteo RP, Brennan MF, Blumgart LH, Jarnagin WR, D'Angelica MI: Survival after hepatic resection for metastatic colorectal cancer: trends in outcomes for 1,600 patients during two decades at a single institution. J Am Coll Surg 2010;210:744-752; discussion 752-755.

2 Tomlinson JS, Jarnagin WR, DeMatteo RP, Fong $\mathrm{Y}$, Kornprat $\mathrm{P}$, Gonen $\mathrm{M}$, Kemeny N, Brennan MF, Blumgart LH, D'Angelica M: Actual 10-year survival after resection of colorectal liver metastases defines cure. J Clin Oncol 2007;25:4575-4580.
} 
-3 de Haas RJ, Wicherts DA, Andreani P, Pascal G, Saliba F, Ichai P, Adam R, Castaing D, Azoulay D: Impact of expanding criteria for resectability of colorectal metastases on shortand long-term outcomes after hepatic resection. Ann Surg 2011;253:1069-1079.

-4 Mayo SC, de Jong MC, Pulitano C, Clary BM, Reddy SK, Gamblin TC, Celinksi SA, Kooby DA, Staley CA, Stokes JB, Chu CK, Ferrero A, Schulick RD, Choti MA, Mentha G, Strub J, Bauer TW, Adams RB, Aldrighetti L, Capussotti L, Pawlik TM: Surgical management of hepatic neuroendocrine tumor metastasis: results from an international multi-institutional analysis. Ann Surg Oncol 2010;17:31293136.

5 Sarmiento JM, Heywood G, Rubin J, Ilstrup DM, Nagorney DM, Que FG: Surgical treatment of neuroendocrine metastases to the liver: a plea for resection to increase survival. J Am Coll Surg 2003;197:29-37.

6 Chamberlain RS, Canes D, Brown KT, Saltz L, Jarnagin W, Fong Y, Blumgart LH: Hepatic neuroendocrine metastases: does intervention alter outcomes? J Am Coll Surg 2000;190: 432-445.

7 Adam R, Chiche L, Aloia T, Elias D, Salmon R, Rivoire M, Jaeck D, Saric J, Le Treut YP, Belghiti J, Mantion G, Mentha G: Hepatic resection for noncolorectal nonendocrine liver metastases: analysis of 1,452 patients and development of a prognostic model. Ann Surg 2006;244:524-535.

8 Ruys AT, Tanis PJ, Nagtegaal ID, van Duijvendijk P, Verhoef C, Porte RJ, van Gulik TM: Surgical treatment of renal cell cancer liver metastases: a population-based study. Ann Surg Oncol 2011;18:1932-1938.

\9 Roh HJ, Kim DY, Joo WD, Yoo HJ, Kim JH, Kim YM, Kim YT, Nam JH: Hepatic resection as part of secondary cytoreductive surgery for recurrent ovarian cancer involving the liver. Arch Gynecol Obstet 2011;284:1223-1229.

-10 van Walsum GA, de Ridder JA, Verhoef C, Bosscha K, van Gulik TM, Hesselink EJ, Ruers TJ, van den Tol MP, Nagtegaal ID, Brouwers M, van Hillegersberg R, Porte RJ, Rijken AM, Strobbe LJ, de Wilt JH: Resection of liver metastases in patients with breast cancer: survival and prognostic factors. Eur J Surg Oncol 2012;38:910-917.

11 Groeschl RT, Nachmany I, Steel JL, Reddy SK, Glazer ES, de Jong MC, Pawlik TM, Geller DA, Tsung A, Marsh JW, Clary BM, Curley SA, Gamblin TC: Hepatectomy for noncolorectal non-neuroendocrine metastatic cancer: a multi-institutional analysis. J Am Coll Surg 2012;214:769-777.

12 de Ridder J, van Walsum M, Verhoef C, Nagtegaal I, de Wilt J; Dutch Liver Working Group: Hepatic resection for metastatic melanoma in The Netherlands: survival and prognostic factors. Melanoma Res 2013;23:27-32.

$\checkmark 13$ Poon RT, Fan ST, Lo CM, Liu CL, Lam CM, Yuen WK, Yeung C, Wong J: Improving perioperative outcome expands the role of hepatectomy in management of benign and malig- nant hepatobiliary diseases: analysis of 1222 consecutive patients from a prospective database. Ann Surg 2004;240:698-708; discussion 708-710.

14 Jarnagin WR, Gonen M, Fong Y, DeMatteo RP, Ben-Porat L, Little S, Corvera C, Weber S, Blumgart LH: Improvement in perioperative outcome after hepatic resection: analysis of 1,803 consecutive cases over the past decade. Ann Surg 2002;236:397-406; discussion 406407.

15 Dimick JB, Cowan JA Jr, Knol JA, Upchurch GR Jr: Hepatic resection in the united states: indications, outcomes, and hospital procedural volumes from a nationally representative database. Arch Surg 2003;138:185-191.

16 Nordlinger B, Sorbye H, Glimelius B, Poston GJ, Schlag PM, Rougier P, Bechstein WO, Primrose JN, Walpole ET, Finch-Jones M, Jaeck D, Mirza D, Parks RW, Collette L, Praet M, Bethe U, Van Cutsem E, Scheithauer W, Gruenberger T: Perioperative chemotherapy with FOLFOX4 and surgery versus surgery alone for resectable liver metastases from colorectal cancer (EORTC intergroup trial 40983): a randomised controlled trial. Lancet 2008;371:1007-1016.

17 Adam R, Delvart V, Pascal G, Valeanu A, Castaing D, Azoulay D, Giacchetti S, Paule B, Kunstlinger F, Ghemard O, Levi F, Bismuth $\mathrm{H}$ : Rescue surgery for unresectable colorectal liver metastases downstaged by chemotherapy: a model to predict long-term survival. Ann Surg 2004;240:644-657; discussion 657-658.

18 Dexiang Z, Li R, Ye W, Haifu W, Yunshi Z, Qinghai Y, Shenyong Z, Bo X, Li L, Xiangou P, Haohao L, Lechi Y, Tianshu L, Jia F, Xinyu Q, Jianmin X: Outcome of patients with colorectal liver metastasis: analysis of 1,613 consecutive cases. Ann Surg Oncol 2012;19: 2860-2868.

19 Brouquet A, Abdalla EK, Kopetz S, Garrett CR, Overman MJ, Eng C, Andreou A, Loyer EM, Madoff DC, Curley SA, Vauthey JN: High survival rate after two-stage resection of advanced colorectal liver metastases: response-based selection and complete resection define outcome. J Clin Oncol 2011;29: 1083-1090.

-20 Nordlinger B, Van Cutsem E, Rougier P, Kohne CH, Ychou M, Sobrero A, Adam R, Arvidsson D, Carrato A, Georgoulias V, Giuliante F, Glimelius B, Golling M, Gruenberger T, Tabernero J, Wasan H, Poston G: Does chemotherapy prior to liver resection increase the potential for cure in patients with metastatic colorectal cancer? A report from the European Colorectal Metastases Treatment Group. Eur J Cancer 2007;43:20372045.

21 Morris EJ, Forman D, Thomas JD, Quirke P, Taylor EF, Fairley L, Cottier B, Poston G: Surgical management and outcomes of colorectal cancer liver metastases. Br J Surg 2010;97: 1110-1118.

22 Manfredi S, Lepage C, Hatem C, Coatmeur O, Faivre J, Bouvier AM: Epidemiology and management of liver metastases from colorectal cancer. Ann Surg 2006;244:254-259.

23 Casparie M, Tiebosch AT, Burger G, Blauwgeers $\mathrm{H}$, van de Pol A, van Krieken JH, Meijer GA: Pathology databanking and biobanking in The Netherlands, a central role for PALGA, the nationwide histopathology and cytopathology data network and archive. Cell Oncol 2007;29:19-24.

24 Lee CR, Lim JH, Kim SH, Ahn SH, Park YN, Choi GH, Choi JS, Kim KS: A comparative analysis of hepatocellular carcinoma after hepatic resection in young versus elderly patients. J Gastrointest Surg 2012;16:17361743.

25 Cannon RM, Martin RC, Callender GG, McMasters KM, Scoggins CR: Safety and efficacy of hepatectomy for colorectal metastases in the elderly. J Surg Oncol 2011;104:804-808.

26 Tsujita E, Utsunomiya T, Yamashita Y, Ohta M, Tagawa T, Matsuyama A, Okazaki J, Yamamoto M, Tsutsui S, Ishida T: Outcome of hepatectomy in hepatocellular carcinoma patients aged 80 years and older. Hepatogastroenterology 2012;59:1553-1555.

27 Pawlik TM, Schulick RD, Choti MA: Expanding criteria for resectability of colorectal liver metastases. Oncologist 2008;13:51-64.

28 Kanas GP, Taylor A, Primrose JN, Langeberg WJ, Kelsh MA, Mowat FS, Alexander DD, Choti MA, Poston G: Survival after liver resection in metastatic colorectal cancer: review and meta-analysis of prognostic factors. Clin Epidemiol 2012;4:283-301.

29 Wicherts DA, de Haas RJ, Andreani P, Sotirov D, Salloum C, Castaing D, Adam R, Azoulay D: Impact of portal vein embolization on long-term survival of patients with primarily unresectable colorectal liver metastases. Br J Surg 2010;97:240-250

-30 Leung EY, Roxburgh CS, Leen E, Horgan PG: Combined resection and radiofrequency ablation for bilobar colorectal cancer liver metastases. Hepatogastroenterology 2010;57: 41-46.

- 31 Bowers KA, O'Reilly D, Bond-Smith GE, Hutchins RR: Feasibility study of two-stage hepatectomy for bilobar liver metastases. Am J Surg 2012;203:691-697.

32 van der Pool AE, Damhuis RA, Ijzermans JN, de Wilt JH, Eggermont AM, Kranse R, Verhoef C: Trends in incidence, treatment and survival of patients with stage IV colorectal cancer: a population-based series. Colorectal Dis 2012;14:56-61.

33 van der Geest LG, Lam-Boer J, Koopman M, Verhoef C, Elferink MA, de Wilt JH: Nationwide trends in incidence, treatment and survival of colorectal cancer patients with synchronous metastases. Clin Exp Metastasis 2015;32:457-465.

34 Lemmens V, van Steenbergen L, Janssen-Heijnen M, Martijn H, Rutten H, Coebergh JW: Trends in colorectal cancer in the south of the Netherlands 1975-2007: rectal cancer survival levels with colon cancer survival. Acta Oncol 2010;49:784-796. 
35 Elferink MA, de Jong KP, Klaase JM, Siemerink EJ, de Wilt JH: Metachronous metastases from colorectal cancer: a population-based study in North-East Netherlands. Int J Colorectal Dis 2015;30:205-212.

36 Lam-Boer J: Large variation in the utilization of liver resections in stage IV colorectal cancer patients with metastases confined to the liver. Eur J Surg Oncol 2015;41:1217-1225.

37 Homayounfar K, Bleckmann A, Helms HJ, Lordick F, Ruschoff J, Conradi LC, Sprenger T, Ghadimi M, Liersch T: Discrepancies between medical oncologists and surgeons in as- sessment of resectability and indication for chemotherapy in patients with colorectal liver metastases. Br J Surg 2014;101:550-557.

38 Jones RP, Vauthey JN, Adam R, Rees M, Berry D, Jackson R, Grimes N, Fenwick SW, Poston GJ, Malik HZ: Effect of specialist decisionmaking on treatment strategies for colorectal liver metastases. Br J Surg 2012;99:1263-1269.

39 Folprecht G, Gruenberger T, Bechstein WO, Raab HR, Lordick F, Hartmann JT, Lang H, Frilling A, Stoehlmacher J, Weitz J, Konopke R, Stroszczynski C, Liersch T, Ockert D, Herrmann T, Goekkurt E, Parisi F, Kohne CH:
Tumour response and secondary resectability of colorectal liver metastases following neoadjuvant chemotherapy with cetuximab: the CELIM randomised phase 2 trial. Lancet Oncol 2010;11:38-47.

40 Tan MC, Jarnagin WR: Surgical management of non-colorectal hepatic metastasis. J Surg Oncol 2014;109:8-13.

41 Tol JA, van Gulik TM, Busch OR, Gouma DJ: Centralization of highly complex low-volume procedures in upper gastrointestinal surgery. A summary of systematic reviews and metaanalyses. Dig Surg 2012;29:374-383. 